\title{
Reaching Out For Everyday Life Creativity
}

\author{
Lene Tanggaard \\ Aalborg University, Denmark \\ E-mail: lenet@id.aau.dk
}

\section{ARTICLE INFO}

\section{Keywords:}

Everyday creativity

Cultural psychology of creativity

Sociomateriality of creativity

\section{Article history:}

Received 2 October 2014

Received in revised form 18 December 2014

Accepted 19 December 2014

ISSN: 2354-0036

DOI: $10.1515 /$ ctra-2015-0011

\section{A B STRACT}

In recent years, a move towards social, culturalpsychological and distributed research perspectives on creativity has been witnessed within the social- and human sciences. Glăveanu is one of the most prominent advocates for this new line of research. In the present commentary, I will share my concerns as to why this move is important and vital for the field of creativity research, but I will also raise my sense of fear by the proposed direction of model unity and coherence as suggested by Glăveanu. On the contrary, we may need to tolerate and respect the diversity of perspectives and enjoy the fruits of cross-disciplinarily research, not needing to reach any state of unity. In this sense, a way out of 'crisis' could be that we respect, variations and even differences, and instead of coherence establish meeting places and spots where divergent perspectives can be celebrated.

When one of the editors of this journal, Maciej Karwowski, asked me to comment on Vlad Glăveanu's latest paper in this journal, I had to ask him a very concrete question. Will I have to be critical of Glăveanu's approach? Maciek wrote back to me immediately. No, you do not have to be very critical, as we have invited other commentators who will maybe take the more critical position. I was quite relieved, as I find myself very close to the position Glăveanu takes in the paper, voicing the need for more coherent work within the field of creativity research, with more considered theoretical and methodological discussion in line with more considered definitions of creativity.

\section{Reaching out for everyday life}

If I were to sum up the position of Glăveanu, it is all about reaching out for everyday life in the field of creativity research, a field that is often locked within the confines of correlational studies or divergent thinking tests. As Glăveanu puts it, citing Torrance, creativity involves every sense - sight, smell, hearing, feeling, taste and even perhaps the extrasensory. Much of it is unseen, nonverbal and unconscious, so broadening the perspective 
of creativity research to involve these dimensions, as well as its more mundane forms is certainly a perspective that resonates with me. We are in need of creativity research that can tell us more about the physicality of the environment and the embodied nature of creative work (see also Tanggaard, 2013; 2014) along the lines of a vision of distributed creativity (Glăveanu, 2014) that does not place creative work outside the mind, but inbetween mind and environment, self and other, the psychological and the material.

Also, I fully agree with the emphasis on the need for more widely encompassing theoretical work and empirical studies formulated in line with this. I also see this position as something which can further develop studies of creativity, not least within my own discipline of psychology, which is where I see Glăveanu's critique being most relevant. I'm not so sure that other disciplines e.g. anthropology, philosophy or history suffer from the same theoretical, methodological and empirical weaknesses underlined by Glăveanu as a general characteristic of creativity research. This is also evident from the studies and papers drawn on by Glăveanu to support his argument for the much needed revitalization of creativity research in light of the 'crisis state of creativity research in psychology'. These references extend to philosophy (Hutchins, 1995; Ingold \& Hallam, 2007) and to educational psychology which is often more cross-disciplinary than basic psychology (Tanggaard, 2013; Plucker, Beghetto \& Dow, 2004).

\section{The importance of socializing creativity}

The basis of Glăveanu's project is essentially to socialize creativity by drawing on the rich tradition of cultural psychology extrapolated by (among others) Valsiner and expand its perspectives to the study of creativity to a higher extent than hitherto seen. By doing so, Glăveanu shares the ambition of other researchers like myself, hoping to spread-out the study of creativity to diverse forms of real-life, everyday life. This enables researchers to study many different practices and thereby limits the risk of reducing creativity to either the ability to think divergently or to produce novel and valuable products. By extending the study of creativity to other kinds of creativity, like for example the creativity involved in making a dinner at home, cleaning the house, making craftwork or, as a teacher, have a class learn something, we can learn more about the process of creativity, the aspects facilitating or hindering creativity and the variations of creativity found in human life and beyond. In my view, this is not a standpoint which needs to critique the existing landscape of cognitively or personality-oriented creativity research, but a perspective that moves in a whole new direction, employing very different sets of epistemological and ontological perspectives than those of traditional creativity research within these disciplines. 


\section{Unity or respecting difference?}

Glăveanu is concerned with making the psychology of creativity stronger and better equipped to continue its growth in the decades to come. One of the problems he addresses is that the discipline contains "plenty of divergence and relatively little (constructive) accumulation". When papers are written, citations mention the same, relatively few, contributors such as Amabile, Runco and Csikszentmihalyi, which does not include the range of perspectives in the field and according to Glăveanu, this leads to excessive idea generation without implementation. I agree with the description of the field, but I'm unsure as to the solution. Are coherence, unity and accumulation of results within the discipline the answer? Is it at all achievable or is the road forward in order to avoid states of crisis in the research field, to respect diversity and maybe even to reach the conclusion that we cannot assume that there is just one field of creativity (within psychology). Indeed, that we may need to tolerate and respect the diversity of perspectives and enjoy the fruits of cross-disciplinarily research, not needing to reach any state of unity. I would thus question the meta-theoretical approach of coherence and unity as a means of crisis dissolution and I'm very sure that Glăveanu will appreciate this, as these kinds of theoretical discussions are certainly what he identifies as missing within the field.

\section{Conclusion}

I share with Glăveanu the ambition to have more studies of creativity in the wild, where the traditional distinction between mind and body and between idea generation and idea implementation becomes obsolete/not necessary. Also, the need to focus on the learning needed to become creative within a given professional field or a school subject and the need to study the developmental aspects of creativity - its temporal and processual dimensions - is something I would like to see explored much further, and for it to become a 'natural' part of the psychology of creativity. This would mean that we would have to start exploring creativity 'forwards', in terms of its movement (Ingold \& Hallam, 2007, p. 2), as underlined in the paper. Indeed, turning the social, organisational and educational arenas into an open laboratory is a clear necessity for creativity research, even if this means going out of one's comfort zone and challenging current ways of thinking and doing research. However, I do not believe that the way out of 'crisis' requires a turn towards unity and accumulation, but would rather suggest that we respect, variations and even differences, and instead of coherence establish meeting places and spots where divergent perspectives can be celebrated. This would of course require that the field in itself and its journals and publishers also accept and respect these differences instead of discounting particular kinds of research as not legitimate. 


\section{REFERENCES}

Glăveanu, V. (2014). The Psychology of Creativity: A Critical Reading Creativity. Theories - Research - Applications, 1, 1, 10-32; DOI: 10.15290/ctra.2014.01.01.02.

Hutchins, E. (1995). Cognition in the wild. Cambridge, MA: MIT Press.

Ingold, T. \& Hallam, E. (2007). Creativity and cultural improvisation: An introduction. In E. Hallam \& T. Ingold (Eds.), Creativity and cultural improvisation (pp. 1-24). Oxford: Berg. Plucker, J. A., Beghetto, R. A. \& Dow, G. T. (2004). Why isn't creativity more important to educational psychologists? Potentials, pitfalls, and future directions in creativity research. Educational Psychologist, 39, 2, 83-96.

Pope, R. (2005). Creativity: Theory, history, practice. London \& New York, NY: Routledge.

Tanggaard, L. (2013). The sociomateriality of creativity in everyday life. Culture \& Psychology, 19, 1, 20-32.

Tanggaard, L. (2014). Fooling around: Creative learning pathways. Charlotte: Information Age Publishers.

Corresponding author at: Lene Tanggaard, The Center for Qualitative Studies The International Center for the Cultural Psychology of Creativity, Aalborg University, Kroghstræde 3, 9220 Aalborg, Denmark

E-mail: lenet@hum.aau.dk 